\title{
Effects of the Selective Laser Melting Process Parameters on the Functional Properties of the Co-Cr Alloy
}

\author{
http://dx.doi.org/10.3991/ijes.v3i1.4291 \\ D. Grzesiak and M. Krawczyk \\ West Pomeranian University of Technology, Szczecin, Poland
}

\begin{abstract}
The purpose of the present study is to investigate the impact of technological parameters on the mechanical properties of the Co-Cr alloy after the Selective Laser Melting (SLM) process. The energy density (E) and the number of the laser beam passes on each melted layer were the variables. The static tensile test was used to evaluate the mechanical properties of the manufactured samples. The results of the study show significant differences in material characteristics resulting from different number of the laser beam passes over the programmed path.
\end{abstract}

Index Terms-CoCr, energy density, laser, Selective Laser Melting.

\section{INTRODUCTION}

In recent years a dynamic development of the modern manufacturing technologies, enabling quality improvement and increase of geometric complexity of manufactured products and reducing the time required to put them on the market, is observed. Among them the additive manufacturing technologies, classified at the beginning as the methods of rapid prototyping (RP) [1], which is often called 3D printing, deserve a special attention. Now they constitute a distinct group of methods more and more widely used in industry and being the subject of many scientific studies.

One of the fastest growing manufacturing technologies is the method of Selective Laser Melting (SLM) [1-5]. SLM is a widely used method for manufacturing threedimensional parts by the selective melting of metal powder layer by layer using a laser $[2,6,7]$. This method, compared to laser sintering (SLS), requires a higher energy level, which is usually achieved by using high power laser and thin layer of powder [2]. In the preparation by SLM technology the geometric models generated by the CAD software are directly used $[1,6,8,9]$. Thanks to this, the method has almost unlimited possibilities with regard to the shape of the final product.

High efficiency of the process, high density, good anticorrosive properties, good aesthetic appearance, the possibility of using many types of materials (i.a. metal matrix nanocomposites [10-13]) and the possibility to individualize the process influenced the application of this technique to the production of prosthetic restorations and attracted the attention of dentists $[6,14,17]$. In prosthetic dentistry, most of the research on SLM method focused on $\mathrm{Co}-\mathrm{Cr}$ alloys [9], from which the elements so far were obtained by casting [6]. It is worth adding that the $\mathrm{Co}-\mathrm{Cr}$ alloys have good corrosion resistance, good wear resistance and excellent biocompatibility $[2,8]$.

The use of SLM process for the production of implants entails many challenges, which can include obtaining high density, full control of the manufacturing process, appropriate hardness and wear resistance.

This articles presents the results of research on the effects of technological parameters of the SLM process on the mechanical properties of the samples made of $\mathrm{CoCr}$ ASTM F75 alloy.

\section{MATERIALS AND METHODS}

The samples were made of the CoCr ASTM F75 alloy powder supplied by the REALIZER device manufacturer. The chemical composition of the alloy is presented in table I. During the experiment, twelve sets of samples were made. Each set contained six samples. Sets differed in the volumetric energy density delivered by the laser beam $\left(\varepsilon\left[\mathrm{J} / \mathrm{mm}^{3}\right]\right)$, which is expressed by (1) and depends on the following technological parameters of the SLM process: laser power $-\mathrm{P}(\mathrm{W})$, velocity of the laser beam movement on the path $-\mathrm{V}(\mathrm{mm} / \mathrm{s})$, distance between the laser beam paths $-\mathrm{h}(\mathrm{mm})$, thickness of the melted layer $\mathrm{d}(\mathrm{mm})$.

$$
\varepsilon=P /(V \cdot h \cdot d)
$$

The velocity of the laser beam movement is expressed by (2) and depends on the following parameters: distance between the laser beam pulses - a ( $\mathrm{mm})$, laser beam exposition time on a single point $-\mathrm{t}(\mathrm{s})$.

$$
V=a / t
$$

The mining of these parameters are described in Fig. 1.

An additional sample variation was the number of the laser beam passes $(\mathrm{X})$ on computed paths. In the first case, the laser beam moved one time on each path, in the second case - two times. The full set of the samples and corresponding technological parameters are shown in table II.

The tensile bars were manufactured by the REALIZER II 250 (MTT-Group) device, equipped with $100 \mathrm{~W}$ Nd:YAG fiber laser. The SLM process scheme and the meaning of characteristic parameters are shown in Fig. 1. During the SLM process, the powder was applied in layers of $30 \mu \mathrm{m}$. On each layer, the powder was melted by laser beam at the locations corresponding to the cross section of 
TABLE I.

CHEMICAL COMPOSITION OF THE CO-CR ASTM F75 AlLOY

\begin{tabular}{|l|c|}
\hline Element & Content \\
\hline Chromium, Cr & $27-30 \%$ \\
\hline Molybdenum, Mo & $5-7 \%$ \\
\hline Nickel, Ni & $<0,5 \%$ \\
\hline Iron, Fe & $<0,75 \%$ \\
\hline Carbon, C & $<0,35 \%$ \\
\hline Silicone, Si & $<1 \%$ \\
\hline Manganese, Mn & $<1 \%$ \\
\hline Tungsten, W & $<0,2 \%$ \\
\hline Phosphorus, P & $<0,02 \%$ \\
\hline Sulphur, S & $<0,01 \%$ \\
\hline Nitrogen, N & $<0,25 \%$ \\
\hline Aluminium, Al. & $<0,1 \%$ \\
\hline Titanium, Ti & $<0,1 \%$ \\
\hline Boron, B & $<0,01 \%$ \\
\hline Cobalt, Co & Balance \\
\hline
\end{tabular}

TABLE II.

CHEMICAL COMPOSITION OF THE CO-CR ASTM F75 Alloy

\begin{tabular}{|c|c|c|c|c|c|c|}
\hline $\begin{array}{c}\text { Sample } \\
\text { variant }\end{array}$ & $\begin{array}{c}\mathbf{P} \\
(\mathbf{W})\end{array}$ & $\begin{array}{c}\mathbf{V} \\
(\mathbf{m m} / \mathbf{s})\end{array}$ & $\begin{array}{c}\mathbf{h} \\
(\mathbf{m m})\end{array}$ & $\begin{array}{c}\mathbf{d} \\
(\mathbf{m m})\end{array}$ & $\begin{array}{c}\boldsymbol{\varepsilon} \\
\left(\mathbf{J} / \mathbf{m m}^{3}\right)\end{array}$ & $\mathbf{X}$ \\
\hline $1 \times 1$ & 100 & 601 & 0,12 & 0,03 & 46,2 & 1 \\
\hline $1 \times 2$ & 100 & 601 & 0,12 & 0,03 & 46,2 & 2 \\
\hline $2 \times 1$ & 100 & 501 & 0,12 & 0,03 & 55,4 & 1 \\
\hline $2 \times 2$ & 100 & 501 & 0,12 & 0,03 & 55,4 & 2 \\
\hline $3 \times 1$ & 100 & 430 & 0,12 & 0,03 & 64,6 & 1 \\
\hline $3 \times 2$ & 100 & 430 & 0,12 & 0,03 & 64,6 & 2 \\
\hline $4 \times 1$ & 100 & 376 & 0,12 & 0,03 & 73,9 & 1 \\
\hline $4 \times 2$ & 100 & 376 & 0,12 & 0,03 & 73,9 & 2 \\
\hline $5 \times 1$ & 100 & 334 & 0,12 & 0,03 & 83,1 & 1 \\
\hline $5 \times 2$ & 100 & 334 & 0,12 & 0,03 & 83,1 & 2 \\
\hline $6 \times 1$ & 100 & 301 & 0,12 & 0,03 & 92,4 & 1 \\
\hline $6 \times 2$ & 100 & 301 & 0,12 & 0,03 & 92,4 & 2 \\
\hline
\end{tabular}

the sample at a given level. At this stage of the process, newly formed layer was permanently bonded to the so far prepared part of the manufactured element. During the melting of each layer, the laser beam, directed by the mirror system, passes the paths programmed by the control computer.

After the SLM process was finished and specimen supports removed, the samples were finished according to the standard procedure.

The mechanical characteristics of the CoCr alloy samples produced by the SLM process were tested on the INSTRON 8501 testing system and Vickers Hardness Tester LECO LV700AT. Tensile tests were performed at the deformation velocity of $0.5 \mathrm{~mm} / \mathrm{min}$ and the data rate $10 \mathrm{pts} / \mathrm{sec}$. Vickers Hardness measures were performed using a load of $30 \mathrm{kG}$.

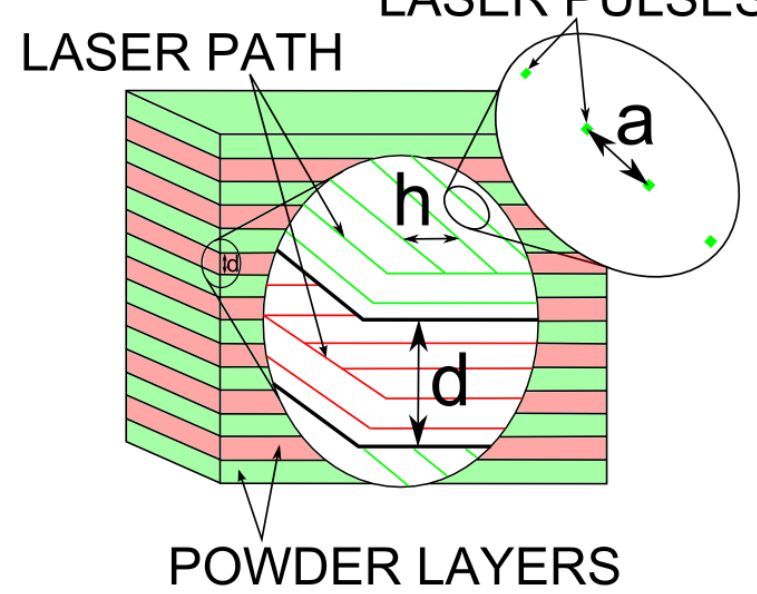

Figure 1. The SLM process scheme: a - distance between the laser beam pulses, $\mathrm{h}$ - distance between the laser beam paths, $\mathrm{d}$ - thickness of single layer

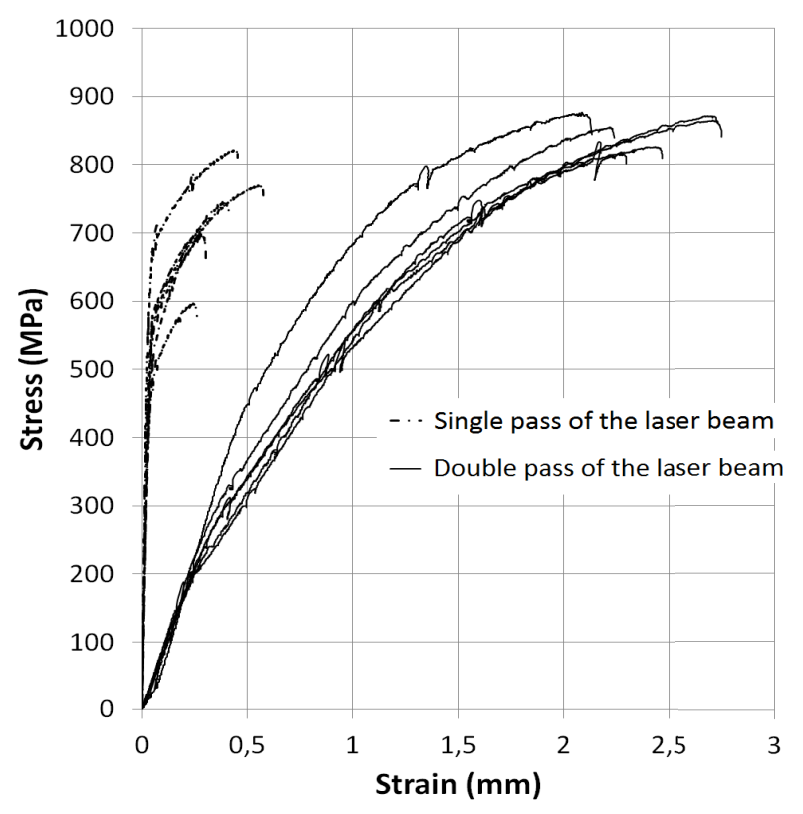

Figure 2. Tensile curves for both of the sample groups

\section{RESULT AND DISCUSSION}

The results obtained from the tensile tests are presented in Fig. 2. The figure shows tensile curve diagrams obtained for one sample chosen from each set, for which the ultimate strength $(\mathrm{Rm})$ value was closest to the mean value for the whole set. The comparison of tensile test results shows significant differences in material characteristics as a result of different number of laser beam passes over the programmed path.

Samples with double pass of the laser beam are much more tensile. Moreover, the shape of tensile curves obtained for one time melted samples is more similar to the typical steels than to the $\mathrm{CoCr}$ alloy - there are distinct linear and nonlinear stages of stress - strain dependency.

Fig. 3 and Fig. 4 shows the same curves labeled with an energy density delivered by the laser beam. 


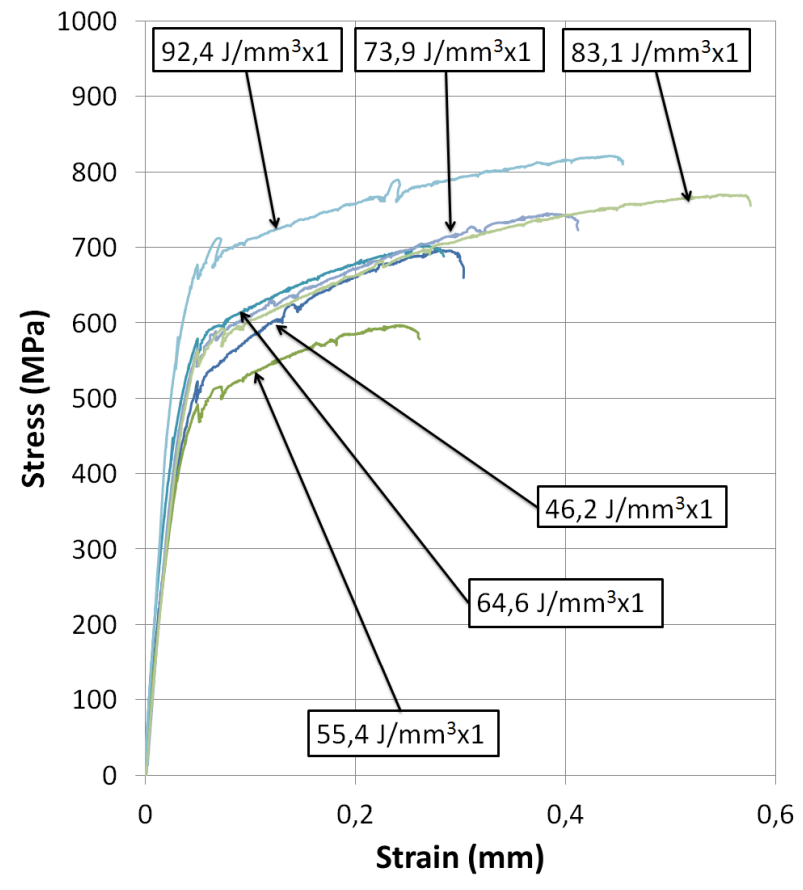

Figure 3. Tensile curve diagrams obtained for the samples on which one laser beam pass over each patch was used.

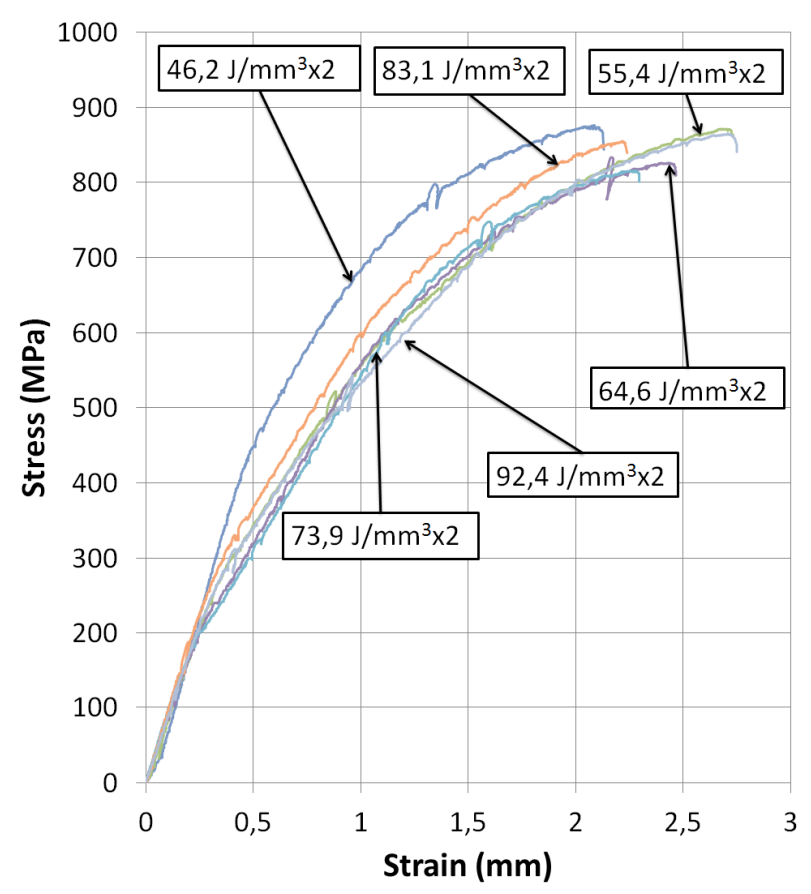

Figure 4. Tensile curve diagrams for the samples on which two laser beam passes over each path were used.

The mean Rm and HV values (Fig. 5 and Fig. 6) show distinct dependency on energy density in case of samples with single pass of the laser beam and no such dependency in case of samples with double pass of the laser beam. It is also clear that none of the variants of the samples scanned once by the laser reached the Rm values close to the values of this parameter measured for the samples scanned twice. In case of hardness measurements performed on samples with single pass of the laser beam, obtained mean values was in range of $470 \mathrm{HV}$ (for low

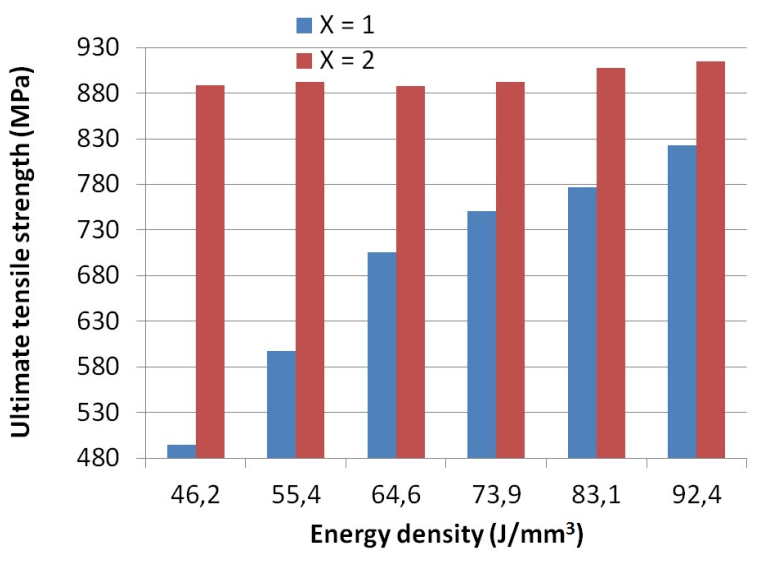

Figure 5. The mean values of the ultimate strength (Rm) obtained for all of the sample variants.

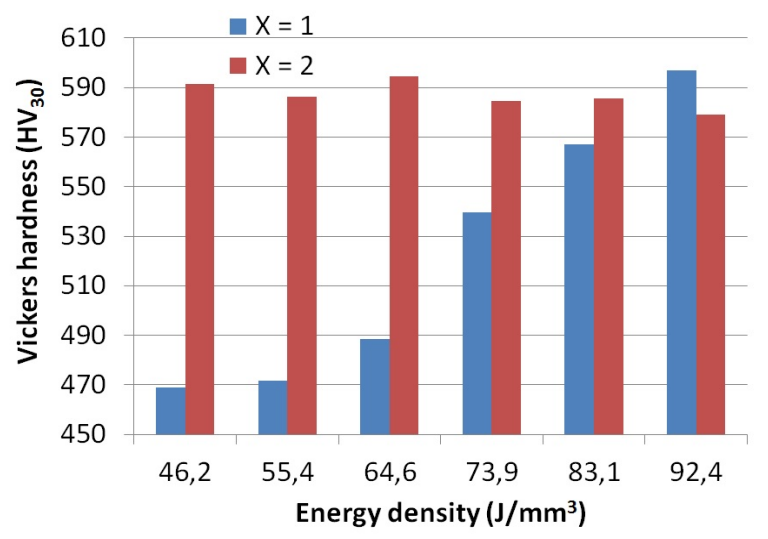

Figure 6. The mean values of the Vickers hardness $\left(\mathrm{HV}_{30}\right)$ obtained for all of the sample variants.

energy density) to $595 \mathrm{HV}$ (for highest energy density value). Hardness of the samples belonging to the second group was in the range of $580-595 \mathrm{HV}$.

\section{CONCLUSION}

The research presented in this paper is focused on the dependency of mechanical properties of CoCr ASTM F75 alloy on the technological parameters of SLM process. The comparison of tensile test and hardness measures results shows significant differences in material characteristics as a result of different number of laser beam passes over the programmed path. Also, in the case of one time scanned samples, the influence of energy density on the tensile strength and hardness is visible.

Values of both measured indicators - ultimate tensile strength and hardness, obtained for almost all prepared samples, are noticeably greater than the values required by the industry standard ASTM F75, which are respectively $655 \mathrm{MPa}$ and 25-35 HRC equivalent to 260-335 HV.

\section{REFERENCES}

[1] K. Osakada and M. Shiomi, "Flexible manufacturing of metallic products by selective laser melting of powder", Int. J. Mach. Tool. Мапu., vol. 46, pp. 1188-1193, 2006.

[2] K. Monroy, J. Delgado and J. Ciurana, 'Study of the pore formation on CoCrMo alloys by selective laser melting manufacturing process', Procedia Engineering, vol. 63, pp. 361-369, 2013. 


\section{SHORT PAPER}

Effects of the Selective Laser Melting Process Parameters on the Functional Properties of the Co-Cr...

[3] D. Wang, Y. Yang., R. Liu, D. Xiao and J. Sun, 'Study on the designing rules and processability of porous structure based on selective laser melting (SLM)', J. Mater. Process. Tech., vol. 213, pp. 1734-1742, 2013.

[4] Y-C. Hagedorn, J. Wilkes, W. Meiners, K. Wissenbach and R. Poprawe, 'Net Shaped High Performance Oxide Ceramic Parts by Selective Laser Melting', Physics Procedia, vol. 5, pp. 587-594, 2010.

[5] X. Su and Y. Yang, 'Research on track overlapping during Selective Laser Melting of powder', J. Mater. Process. Tech., vol. 212, pp. 2074-2079, 2012.

[6] X-Z. Xin, J. Chen, N. Xiang, Y. Gong and B. Wei, 'Surface characteristics and corrosion properties of selective laser melted $\mathrm{Co}-\mathrm{Cr}$ dental alloy after porcelain firing', Dent. Mater., vol. 30, pp. 263-270, 2014.

[7] M. Rombouts, J.P. Kruth, L. Froyen and P. Mercelis, 'Fundamentals of Selective Laser Melting of alloyed steel powders', CIRP Ann. Manuf. Technol., vol. 55 (1), pp. 187-192, 2006.

[8] K. Yamanaka, M. Mori, K. Kuramoto and A. Chiba, 'Development of new Co-Cr-W-based biomedical alloys: Effects of microalloying and thermomechanical processing on microstructures and mechanical properties', Mater. Design, vol. 55, pp. 987-998, 2014. http://dx.doi.org/10.1016/j.matdes.2013.10.052

[9] Al. Jabbari Y.S., T. Koutsoukis, X. Barmpagadaki and S. Zinelis, 'Metallurgical and interfacial characterization of PFM Co-Cr dental alloys fabricated via casting, milling or selective laser melting', Dent. Mater., vol. 30, pp. e79-e88, 2014.

[10] A. Biedunkiewicz, P. Figiel, W. Biedunkiewicz, D. Grzesiak, M. Krawczyk and U. Gabriel-Polrolniczak, 'Mechanical Properties of Metal Matrix Nanocomposites Synthesized by Selective Laser Melting Measured by Depth Sensing Indentation Technique', Key Eng. Mat., vol. 586, pp. 83-86, 2014.

[11] P. Figiel, W. Biedunkiewicz and D. Grzesiak, 'Oxidation process of the steel/nc-TiC nanocomposites', J. Therm. Anal. Calorim., vol. 108, pp. 979-983, 2012.

[12] A. Biedunkiewicz, W. Biedunkiewicz, P. Figiel, D. Grzesiak and M. Jaworska, 'Nanocomposites manufactured by Selective laser melting/Sintering method, reinforced by nanocristalline Fe-Ti-BC powders', 'Nanokompozyty wytwarzane metodą selektywnego stapiania/spiekania umocnione nanokrystalicznymi proszkami w układzie Fe-Ti-BC', Inzynieria Materialowa, vol. 33(6), pp. 330-332 (in Polish) 2012.

[13] A. Biedunkiewicz, W. Biedunkiewicz, P. Figiel and D. Grzesiak, 'Preparation of stainless steel-TiC composite by selective laser melting', Chem. Listy, vol. 105, pp. 773-774, 2011.

[14] N. Xiang, X-Z. Xin, J. Chen and B. Wei, 'Metal-ceramic bond strength of $\mathrm{Co}-\mathrm{Cr}$ alloy fabricated by selective laser melting', J. Dent., vol. 40, pp. 453-457, 2012. http://dx.doi.org/10.1016/ j.jdent.2012.02.006

[15] B-D. Joo, J-H. Jang, J-H. Lee, Y-M. Son and Y-H. Moon, 'Selective laser melting of Fe-Ni-Cr layer on AISI H13 tool steel', T. Nonferr. Metal. Soc., vol. 19, pp. 921-924, 2009.

[16] X.Z. Xin, N. Xiang, J. Chen and B. Wei, 'In vitro biocompatibility of $\mathrm{Co}-\mathrm{Cr}$ alloy fabricated by selective laser melting or traditional casting techniques', Mater. Lett., vol. 88, pp. 101-103, 2012.

[17] N. Xiang, X-Z. Xin, J. Chen and B. Wei, 'Metal-ceramic bond strength of $\mathrm{Co}-\mathrm{Cr}$ alloy fabricated by selective laser melting' Dent. Mater., vol. 40, pp. 453-457, 2012.

[18] D. Gu and Y. Shen, 'Effects of processing parameters on consolidation and microstructure of W-Cu components by DMLS' $J$. Alloy. Compd., vol. 473, pp. 107-115, 2009.

\section{AUTHORS}

D. Grzesiak is with the West Pomeranian University of Technology, Szczecin, Piastow 17 Ave, 70310 Poland (email: dariusz.grzesiak@zut.edu.pl).

M. Krawczyk is with the West Pomeranian University of Technology, Szczecin, Piastow 17 Ave, 70310 Poland (e-mail: marta.krawczyk@zut.edu.pl).

This work was supported in frames of Polish national scientific project, No: N N504 492839, entitled Research on methods of manufacturing irregular lattice structures with application of SLM, financed entirely by National Centre of Science and the Dean's Grant "Young Staff" no: 51706-011-5400/17. It is an extended and modified version of a paper presented at the International Conference on Additive Technologies (ICAT2014), held from 15-17 October 2014 in Vienna, Austria. Submitted 28 November 2014. Published as resubmitted by the authors 10 March 2015. 